\title{
New insights into the mechanism of F-box proteins in colorectal cancer (Review)
}

\author{
JIAN GONG and JIRONG HUO \\ Department of Gastroenterology, The Second Xiangya Hospital of Central South University, \\ Changsha, Hunan 410011, P.R. China
}

Received November 7, 2014; Accepted February 10, 2015

DOI: $10.3892 /$ or.2015.3823

\begin{abstract}
Colorectal cancer (CRC) is one of the most common cancers worldwide with a high incidence and mortality rate. Integrative studies including systematic sequencing of colorectal tumors have provided an unprecedented insight into the molecular basis of CRC. Recently, evidence indicates that F-box proteins (FBPs) play a critical role in the oncogenesis, invasion, metastasis and prognostic assessment of CRC. Therefore, this review discusses the recent literature regarding the function and regulation of FBPs in the pathogenesis of CRC. Furthermore, we highlight that FBPs may represent an attractive therapeutic target for CRC.
\end{abstract}

\section{Contents}

1. Introduction

2. SCF type of E3 ubiquitin ligases

3. FBPs are core components of E3 ubiquitin ligases

4. Possible oncogenes of FBPs, SKP2, FBXL20, $\beta$-TrCP, in CRC

5. Possible tumor suppressor gene, FBXW7, in CRC

6. Conclusions and future direction

\section{Introduction}

CRC is one of the most common malignant tumors and is associated with poor overall survival $(1,2)$. It is estimated that there were 1.2 million new cases and 608,700 deaths worldwide in 2008 (3). CRC is characterized by compounding genetic mutations in both oncogenes and tumor-suppressor genes that drive its initiation and promotion under various

Correspondence to: Dr Jirong Huo, Department of Gastroenterology, The Second Xiangya Hospital of Central South University, Changsha, Hunan 410011, P.R. China

E-mail: huojir008@126.com

Key words: F-box proteins, colorectal cancer, SKP, FBXW7, $\beta$-TrCP pathophysiological conditions. Despite advances in the prevention, early detection and treatment for advanced malignancies (4), the 5-year survival rate of CRC patients with distant metastases has decreased to less than $10 \%$ (5). Currently, CRC is mainly treated using surgery, chemoradiotherapy and biologically targeted therapy. Surgery is still the dominant treatment for CRC, yet many patients develop tumor recurrence after surgery. Chemotherapy is the first-line treatment for advanced CRC; however, chemotherapy drug resistance often results in treatment failure. Taken together, although surgery and chemotherapy are the leading treatments in clinical practice, they are of limited value for advanced CRC patients. Therefore, it is important to explore the mechanisms underlying tumorigenesis in CRC to assess the prognosis and to develop novel efficient primary or adjuvant drugs for CRC. Extensive cancer research over the last decade has uncovered numerous F-box protein (FBP) alterations in CRC.

\section{SCF type of E3 ubiquitin ligases}

E3 ubiquitin ligases are vital components of the ubiquitin-proteasome system (UPS) which governs a broad array of basic cellular processes such as cell proliferation, cell cycle progression, transcription and apoptosis (6). UPS is rather complex and consists of the ubiquitin-activating enzyme (E1), ubiquitin-conjugating enzyme (E2) and ubiquitin ligase (E3). These three enzymes act in concert to exert UPS function (7) (Fig. 1). E1 utilizes ATP to activate ubiquitin for conjugation and transfers it to E2. E2 interacts with a specific E3 partner and transfers the ubiquitin to the target protein, guiding the substrate to be destroyed by the proteasome (8). There are few studies to date, that have linked E1 and E2 to cancer (9). In general, it is FBPs that play a fundamental role in the proper functioning of SCF type E3 ligases for the timely degradation of various substrates thereby ensuring normal cell growth. This may be one of the reasons why deregulation of FBPs often leads to diseases including cancer development.

There are more than 1,000 types of E3 ubiquitin ligases based on the special domains they contain, such as the significantly new gene (RING)-domain, homologous to the E6-AP carboxyl terminus (HECT)-domain, U-box- and PHD-domain (10). Among them, RING-type E3 ligases are the best characterized and the most versatile class type of the E3 ligase complex (11). The SCF complex consists of 


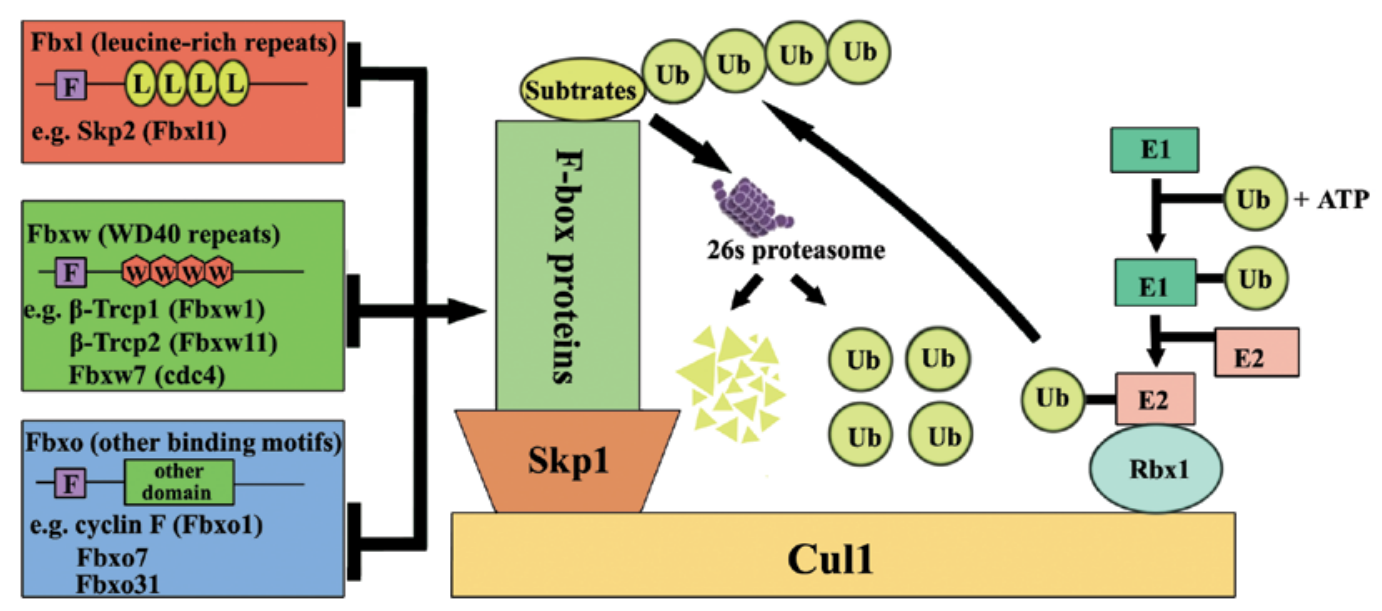

Figure 1. Ubiquitin is first activated by ubiquitin-activating enzyme (E1), then transferred to ubiquitin-conjugating enzyme (E2), and finally transferred to substrates by ubiquitin ligases (E3). The ubiquitin proteins are recognized and then degraded by 26 proteasome to several small peptides. The SCF type of E3 ligase complex consists of Skp1, RbX1, Cullin and a variable F-box protein. In humans, FBPs have been classified into three categories according to their specific substrate recognition domains. FBXL family proteins are those with Leu-rich repeat domains. FBXW family proteins are those with WD40 domain. The remaining F-box proteins that contain other diverse protein-interaction domains or no recognizable domains are called FBXO family proteins. FBPs, F-box proteins.

four components: an adaptor subunit (Skp1), a RING-domain protein (RbX1/Roc1), a scaffold protein (Cullin1/Cullin) and a variable subunit denoted as FBP that binds the substrate. Above all, substrate-specific degradation is a main feature of the UPS.

\section{FBPs are core components of E3 ubiquitin ligases}

FBPs are the substrate recruiting components of E3 ubiqutinligase complexes, and they determine target specificity through recognition and binding target proteins for ubiquitination and then degradation. It is FBPs that are involved in cellular physiological processes through degradation of its ubiquitination protein. FBPs contain an N-terminal, an F-box domain and a C-terminal. The $\mathrm{N}$-terminal is a 48 -amino acid F-box domain, which binds SKP1 to create a link to Cullin1. The C-terminal is a variable protein-interaction domain, such as Trp-Asp repeats (also called WD40) and leucine-rich repeats (LRR), as well as unknown motifs, which are responsible for identifying specific substrates (12). According to the variable C-terminal, FBPs can be categorized into three subclasses, FBXW, FBXL and FBXO, family proteins. In humans, FBXW family proteins are those with the WD40 domain, which is composed of 10 proteins, and the FBXL family proteins are those with a Leu-rich repeat domain comprising 22 proteins. The remaining 37 F-box proteins with other diverse proteininteraction domains or no recognizable domains are called FBXO family proteins (Fig. 1). Research has elucidated that the aberrant regulation of FBPs is clinically related to the occurrence and development of cancers. For example, SKP2, a representative of the FBXL family proteins, is always highly expressed in cancers, while FBXW7, one member of the FBXW family, is often downregulated in cancers. Whether FBPs exert an antitumoral or a promoting effect depends on the specific substrates that they degrade. FBPs function as oncoproteins when overexpressed if their substrates are tumor suppressors or as tumor suppressors if their substrates are oncoproteins. Each FBP has more than one substrate; for the same reason, one substrate can be degraded by different FBPs. F-box protein FBXO31 mediates the degradation of cyclin D1 in melanoma cells (13). In the breast cancer cell line MCF-7, cyclin D1 is degraded by the APC/cdc27 complex (14). Cyclin D1 is degraded by FBXW8 in the CRC cell line HCT116 (15). In addition, FBXO31 is downregulated in breast (16), liver (17) and gastric cancer (18). However, an opposite result was discovered in esophageal squamous cell carcinoma (ESCC). Kogo et al (19) showed that higher FBXO31 expression levels were significantly correlated with elevated tumor invasion and clinical stage and determine a poorer prognosis when compared with low expression. Therefore, the roles of FBPs in cancers are intricate. This review focuses on the current understanding of FBPs in CRC.

\section{Possible oncogenes of FBPs, SKP2, FBXL20, $\beta$-TrCP, in CRC}

SKP2. S-phase kinase-associated protein 2 (SKP2) gene, located on chromosome $5 \mathrm{p} 13$, is mainly responsible for ubiquitylation and subsequent degradation of cell cycle regulators, in particular the cell cycle inhibitor p27 (Kip1). p27 (Kip1) is a negative regulator of the cell cycle that plays an important role in tumor suppression. SKP2 was originally discovered in 1995 due to its ability to interact with the cell cycle protein cyclin A (20). Most published studies have found that SKP2 is overexpressed in various tumor tissues and cell lines with downregulation of p27 expression (21-25). SKP2 was also found to be highly associated with histological grade, tumor size (26) and tumor metastasis (27-30) in these cancers. Over the past decade, overwhelming evidence has emerged supporting a role for SKP2 to function as an oncogene and an independent prognostic marker for disease-free survival and overall survival in patients diagnosed with cancer.

SKP2 protein overexpression interacts with ras mutations to exert an independent adverse prognostic impact on non-small cell lung carcinoma (31). A previous study (32) reported that SKP2 overexpression could only transform primary rat embryo 
fibroblasts when H-ras was also coexpressed. Furthermore, although the expression of SKP2 or N-ras alone failed to induce malignancy, the coexpression of SKP2 and N-ras was capable of inducing lymphoma (33). Both results indicated that SKP2 overexpression might function differently between normal ras and mutant ras cancers. Nevertheless, there is no literature to implicate their application in the clinical decision process for the appropriateness of adding adjuvant therapy in cancers.

Hershko et al (21) identified an inverse correlation between levels of SKP2 mRNA/protein and p27 (Kip1) in colorectal carcinomas. However, this relationship was not found in cervical cancer (34). Overexpression of SKP2 was observed in aggressive CRC and was responsible for downregulation of p27 levels (35). The data from Shapira et al (36) also confirmed this conclusion. Overexpression of SKP2 was found to be associated with colorectal carcinogenesis and subsequent metastasis to lymph nodes (37). Meanwhile, SKP2 was found to determine poor prognosis in colorectal carcinoma (38). $\mathrm{Xu}$ et al (39) knocked down the expression of SKP2 using an adenovirus expressing SKP2 shRNA in SW480 cells. Their results showed that the knockdown of SKP2 blocked growth and induced cell apoptosis in the CRC cell line SW480. At the same time, their results indicated that SKP2 stimulated colorectal tumor growth by inhibiting p27 and p16 expression. Moreover, the Notch1-dependent regulation of p27 determined cell fate in CRC (40). Tian et al (41) found for the first time that high expression of SKP2 predicted a poor response to neoadjuvant chemoradiotherapy in rectal cancer patients. Bortezomib, a proteasome inhibitor, is a modified dipeptidyl boronic acid derived from leucine and phenylalanine. Its effect on SKP2 suppression and p27 upregulation was demonstrated in the CRC cell lines HT29 and SW480. Oxysterol receptors $\mathrm{LXRa}$ and $\mathrm{LXRb}$ were found to regulate the expression of SKP2 in human colon cancer cells Colo205 and HCT116 (42). SKP2 nuclear ubiquitination-dependent pathway played an important role in the regulation of nuclear p27 (Kip1) expression (43). The high copy amplification of the SKP2 gene was associated with chromosomal instability phenotype in CRC cell line WiDr (44). Moreover, Kleivi et al (45) compared the genetic profile from different tumor stages of $\mathrm{CRC}$, including primary tumors, liver metastasis and peritoneum carcinomatosis, and they found that SKP2 played an important role in the metastatic process.

FBXL20. The FBXL20 gene is located on human chromosome 17q21.2. Zhu et al (46) reported that FBXL20 was involved in CRC tumorigenesis. Initially, this group observed the expression of FBXL20 mRNA in 30 pairs of human colorectal adenocarcinoma tissues and corresponding adjacent normal colorectal tissues. As the result showed, FBXL20 mRNA expression was upregulated in $76.7 \%$ of the tumor samples. Additionally, SET and E-cadherin were ubiquitinated and negatively regulated by FBXL20 in the CRC cell lines SW480 and SW620 which caused cell proliferation and reduced apoptosis. To further confirm the function of FBXL20 in CRC, the authors determined that FBXL20 might mediate the degradation of E-cadherin resulting in an increase in cell viability and invasive ability of the CRC cell line LoVo (47). Taken together, these findings indicate that FBXL20 may also control tumorigenesis in colorectal adenocarcinoma. However, data concerning FBXL20 in the promotion of tumorigenesis in animal models are lacking and further investigation is needed.

$\beta$-transducin repeat-containing protein $(\beta$-TrCP). $\beta$-TrCP has been shown to play important roles in tumorigenesis. Yet, its exact role in cancer remains controversial. $\beta$-TrCP mainly acts as an oncoprotein, yet in some situations as a tumor suppressor, depending on the function of the targeted substrates. Taken together, $\beta$-TrCP may play a greater role as an oncogenic protein than as a tumor suppressor in cancers.

Human $\beta$-TrCP was first identified in 1998 as a binding partner of HIV-1 Vpu protein in a yeast two-hybrid screening. Two typical substrates of $\beta$-TrCP are $\mathrm{I} \kappa \mathrm{B}$ in the $\mathrm{NF}-\kappa \mathrm{B}$ pathway and $\beta$-catenin in the wnt pathway $(48,49)$. IкB, inhibitor of $\mathrm{NF}-\kappa \mathrm{B}$, functions as a tumor suppressor. $\beta$-catenin has been identified as highly stable in various types of human cancers, and is always correlated with poor prognosis and reduced survival $(50,51)$. Since $\mathrm{I} \kappa \mathrm{B}$ and $\beta$-catenin exert antagonistic functions and both exist in cells, it is difficult to make in vivo interpretations only targeting $\beta$-catenin but not I $\kappa$ B. The linkage between $\mathrm{SCF}^{\beta-\mathrm{TRCP}}$ and $\mathrm{NF}-\kappa \mathrm{B}$ makes it a drug target. The development of $\beta$-TrCP inhibitors may be a feasible therapeutic approach for $\mathrm{NF}-\kappa \mathrm{B}$-associated human disease. NF- $\kappa \mathrm{B}$ is held in an inactive form within the cytoplasm through association with IкB. In response to cytokines and other extracellular signals, the IкB kinase complex phosphorylates $\mathrm{I} \kappa \mathrm{B}$, thereby promoting its degradation through the UPS. This allows the relocalization of NF- $\kappa B$ into the nucleus, where it activates the expression of genes important for cytokine and survival responses. The identification of $\mathrm{SCF}^{\beta \text {-TRCP }}$ as the $\mathrm{E} 3$ for I $\mathrm{B}$ suggests that it may be a target for molecules that act as anti-inflammatory agents by blocking I $\kappa$ B degradation. Due to the specific substrate degraded by $\beta$-TrCP, $\beta$-TrCP also participates in cell adhesion and migration (52). Taken together, $\beta$-TrCP is a member of the SCF family with a complex body of literature with both oncogenic and tumorsuppressor properties.

Guardavaccaro et al (53) showed that $\mathrm{I} \kappa \mathrm{B} \alpha$ and $\beta$-catenin were not elevated in the absence of $\beta$-TrCP1 mouse embryonic fibroblasts (MEFs), whose accumulation required additional silencing of $\beta$-TrCP 2 by siRNA. Detailed analyses performed in this study also suggested that $\beta-\operatorname{TrCP} 1$ deletion in the mouse causes male fertility. Another study by Kanarek et al (54) showed that depletion of $\beta$-TrCP2 by inducible small hairpin RNA on a $\beta$-TrCP1 knockout background resulted in a severe testicular phenotype marked by a near absence of spermatids and meiotic cells. They also demonstrated that the two $\beta-\operatorname{TrCP}$ paralogs had a non-redundant role in spermatogenesis. It is generally implicated that $\beta$-TrCP functions in the promotion of various carcinomas (55-58). Moreover, many $\beta$-TRCP substrates are known tumor suppressors such as IкB (59) and FOXO3 (60). Finally, genetic depletion of $\beta$-TrCP1 shows no phenotype in mice (61). $\beta$-TrCP1 was found in $56 \%(25 / 45)$ of CRC tissues compared to normal colorectal tissues (56). Increased $\beta$-TrCP1 levels were significantly associated with $\beta$-catenin activation. This result indicated that $\beta$-TrCP1 acts as an oncogene in CRC. However, in sharp contrast to the tumor-promoting role in $\mathrm{CRC}, \beta$-TrCP has been shown to act as an oncogenic protein in other cancers such as gastric 
cancer $(62,63)$. An analysis of somatic mutations in 95 gastric cancer specimens found 5 missense mutations in $\beta$-TrCP2 Moreover in these particular tissues the oncogene $\beta$-catenin level was higher than the controls, indicating that $\beta$-TrCP2 functions as a tumor suppressor in gastric cancer (63). Unfortunately, although multiple groups have tried to investigate the biological roles of $\beta$-TrCP in cancers, the physiological functions of $\beta$-TrCP remain largely elusive. Therefore, further investigation is needed to delineate the exact role of $\beta$-TrCP in tumorigenesis.

\section{Possible tumor suppressor gene, FBXW7, in CRC}

The first member of the FBXW7 gene family, Cdc4, was originally identified in budding yeast as a cell division cycle protein (64). It was then characterized in other species including Homo sapiens (FBW7, also known as FBXW7) (65). The FBXW7 gene is located on chromosome 4 (4q31.3), and it consists of 1 specific exon and 10 common exons. Human FBXW7 encodes three transcripts (FBXW7 $\alpha$, FBXW7 $\beta$ and FBXW7 $\gamma$ ) derived from the alternative N-terminus (66). The three isoforms share conserved interaction domains in the C-terminus, all containing the F-box domain and WD repeat domain. Each isoform is differentially regulated both in tissue expression and cellular locale. FBXW7 $\alpha$ is ubiquitously expressed in all tissues, while FBXW7 $\beta$ is restricted to the brain and testis and FBXW7 $\gamma$ to the heart and skeletal muscles (67). The localization of each isoform also varies within the cell and is located in distinct subcellular compartments. The three FBW7 $\alpha, \beta$ and $\gamma$ isoforms localize to the nucleoplasm, cytoplasm and nucleolus, respectively (68).

FBXW7 is a well-characterized tumor suppressor that is frequently mutated or depleted in a variety of human malignances. FBXW7 exerts its antitumor function through the following ways. Firstly, FBXW7 mediates the degradation of various oncoproteins such as cyclin E, c-Myc, c-Jun and Notch-1, all of which regulate cellular proliferation, differentiation and cause genetic instability in a variety of human tumors. The dysregulation of FBXW7-mediated proteolysis of these substrates contributes to tumorigenesis. Secondly, $6 \%$ of all primary human tumors harbor mutations in the FBXW7 gene (69). Thirdly, FBXW7 mutation is associated with p53 gene mutation (70); FBXW7 and p53 cooperatively suppress advanced and chromosomally unstable intestinal cancer (71).

Roles of FBXW7 in in vitro models. Rajagopalan et al (72) first identified the mutation of hCDC4 in human CRC. They found an increase in cyclin $\mathrm{E}$ protein caused by loss of FBXW7 in the HCT116 or DLD-1 hCDC $^{-/-}$cell line resulting in chromosomal instability. Cyclin $\mathrm{E}$ is a pivotal regulator of cell cycle progression and is frequently upregulated in cancer (73). It was reported that FBXW8 targeted cyclin D1, and FBXW7 targeted cyclin E for degradation in CRC HCT116 and SW480 cells (15). Similar to cyclin E, cyclin D1 is an oncoprotein that was found routinely activated in human types of cancers (74-76). Sionov et al (77) and Grim et al (78) indicated that $\mathrm{FBXW} 7 \alpha$ might be the major isoform that mediates the stability of cyclin E. However, the results from van Drogen et al (79) and Sangfelt et al (80) were different. The latter two research groups hypothesized that both FBXW7 $\alpha$ and $\mathrm{FBXW} 7 \gamma$ were responsible for the degradation of cyclin $\mathrm{E}$; FBXW7 $\alpha$ did not directly mediate cyclin E degradation. Notably, substrate recognition by FBXW7 may be more complex than simple differences in isoform specificity and FBXW isoform dimerization may also have an affect $(81,82)$. CRC LoVo cells depleted of FBXW7 by small interfering RNA underwent overproliferation (83). Fukushima et al (84) demonstrated that FBXW7 promoted NFאB2 ubiquitination and destruction in a GSK3 phosphorylation-dependent manner in both HCT116 and DLD1 CRC cell lines. FBXW7 has also been reported to be regulated by others. Rapamycin-insensitive companion of mTOR (Rictor) binding to FBXW7 regulated ubiquitination and increased protein levels of c-Myc and cylin E in the CRC cell line HCT116 (85). Consistent with this observation, Wang et al (86) also found that the tumor cell lines HCT116 and DLD-1 harboring inactivation of FBXW7 underwent epithelial-mesenchymal transition, and were particularly sensitive to mTOR inhibitor rapamycin. This result indicates that loss of FBXW7 could be a biomarker of human cancer susceptibility to mTOR inhibitor treatment. These results suggest that FBXW7 plays a pivotal role in colon cancer progression and may be used for drug screening.

Roles of FBXW7 in in vivo models. To explore the underlying mechanisms of the development and tumor formation in CRC due to the deregulation of FBXW7, several FBXW7-knockout mouse models have been generated to understand the anticancer function of FBXW7 in CRC. Tetzlaff et al (87) first reported that the functional ablation of $\mathrm{FBXW7} 7^{-/}$resulted in embryonic lethality at around 10.5 days due to major developmental defects. Sancho et al (88) generated gut-specific knockout $\mathrm{FBXW7}^{+/-}$mice lacking one allele of FBXW7 to investigate the function of FBXW7. Their results indicated that the high expression of c-Jun and Notch-1 in the conditional FBXW7-intestine-deficient mice induced actively proliferating progenitor cells in spite of no developed intestinal tumors. The complete absence of FBXW7 $7^{-/}$caused increased tumor number and tumor size. Deletion of FBXW7 in the murine gut altered homeostasis of the intestinal epithelium, resulting in elevated Notch and c-Jun expression, and eventually led to intestinal and colonic polyposis (89). However, FBXW7 deletion alone cannot cause tumorigenesis in the gut, as both FBXW7 and p53 synergistically suppress adenocarcinomas (73). This result provides novel insight for CRC associated with ubiquitin pathway mutations. In support of this finding, Davis et al (90) firstly created an animal model FBXW7 $7^{\mathrm{f}(\mathrm{R} 482 \mathrm{Q}) /+}$, which could faithfully mimic human disease. This model has a stronger ability to increase polyp numbers and size and promote intestinal tumorigenesis on an Apc mutant background. Therefore, loss of FBXW7 combined with overexpression of oncogenes or deletion of tumor-suppressor genes may contribute to cancer under the proper conditions. Morever, the substrate of this model was not c-Jun, but Klf5 and Tgif1 in both normal intestines and adenomas. In addition, absence of $m i R-27 a$ was found to inhibit colon cancer stem cell proliferation in vitro and tumor formation in vivo by increasing FBXW7 protein level (91). A study carried out in breast cancer showed that hypermethylation of the FBXW7 promoter also contributed to inactivation of FBXW7 and was associated with poorly differentiated tumors (92). These results indicated that the upstream 


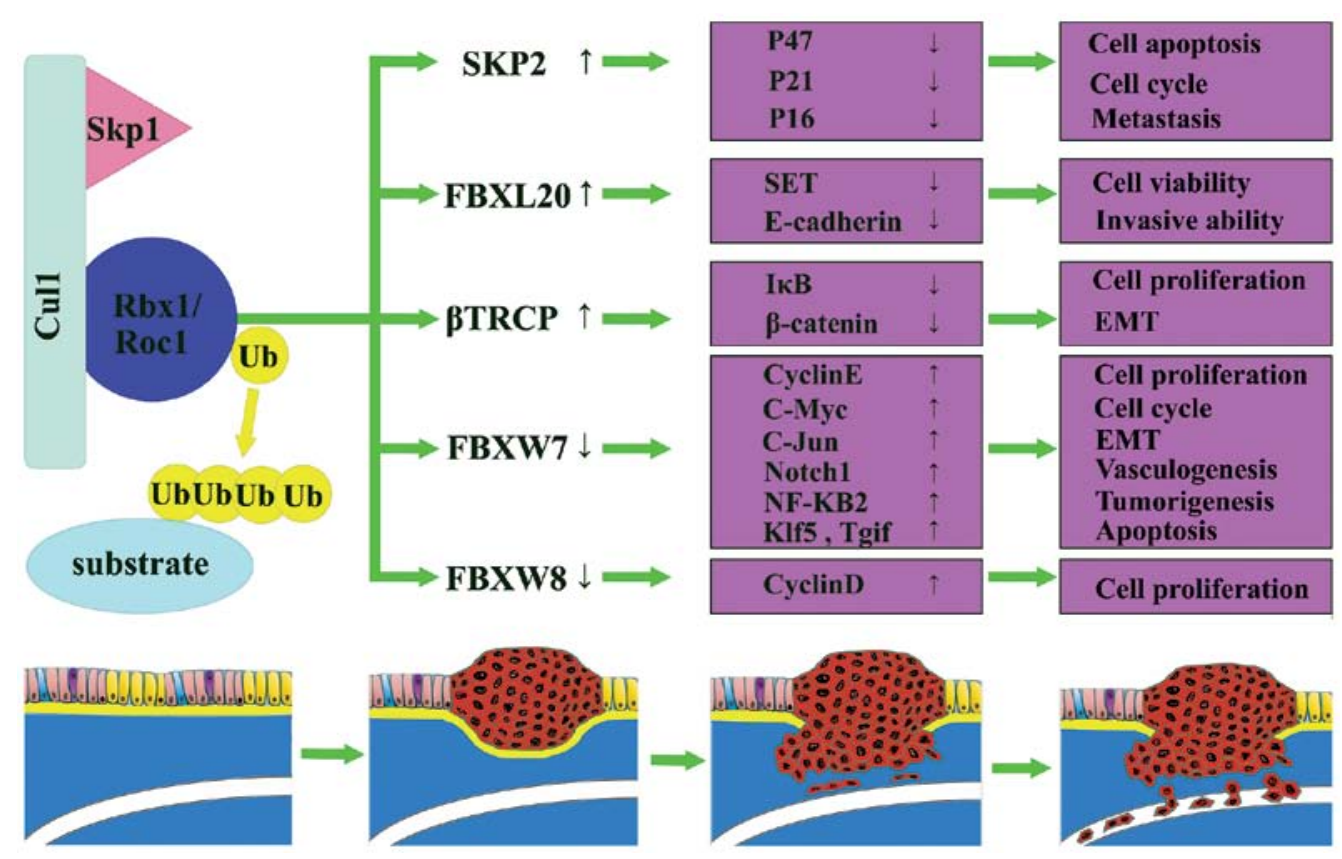

Figure 2. The characterized F-box proteins and their corresponding substrates that are involved in the occurrence and development of colorectal cancer.

regulator was another main factor to influence the function of FBXW7.

Several studies have demonstrated the role of FBXW7 in vivo. However, further in-depth investigation is required to define the exact molecular mechanism underlying the antitumor activity of FBXW7 as well as the mechanism by which the expression of FBXW7 is regulated, and how the loss of FBXW7 contributes to the development or the progression of CRC.

Roles of FBXW7 in CRC tissues. FBXW7 mutations have been thoroughly surveyed in CRC. Rajagopalan et al (74) first reported that the mutation frequency of FBXW7 in CRC was $8 \%$ (44 of 532), which was related with chromosomal instability (CIN) in human types of cancers. The data from Kemp et al (93) confirmed this. They used fluorescence single-strand conformational polymorphism (SSCP) analysis to screen 244 colorectal tumors and 40 cell lines. The results showed that $6 \%$ (18 of 284) of tumors harbored CDC4 mutations. The results differed from the former. Kemp et al believed that FBXW7 mutations were not associated with chromosomal instability. A recent study from Mouradov et al (94) provides an adequate explanation to the contradiction. They insist that microsatellite instability (MSI) and CIN are independent predictors for stage II/III CRC patients rather than specific gene mutations such as KRAS, NRAS, BRAF, PIK3CA, FBXW7 and TP53. Miyaki et al (95) investigated the mutation of FBXW7 in hereditary colorectal tumors. Somatic FBXW7 mutations were detected in $9 \%$ of hereditary non-polyposis CRC (HNPCC) or adenomatous polyposis (FAP) carcinomas. Comparing the FBXW7 mutation rate in flat adenomas to polypoid adenomas, the FBXW7 mutation frequency was 1.13 and $3.23 \%$, respectively (96). FBXW7 mutation was also found to determine poor prognosis in CRC (86). Xie et al (97) performed whole genome sequencing of two primary CRC tumors and their matched liver metastases. Their results indi- cated that FBXW7 contributed to the initiation and progression of distant metastasis. What is more, mutations of FBXW7 in CRC patients usually occur with other simultaneous molecular aberrations such as KRAS; one of the possible explanations why the KRAS mutation frequency in the CRC population was relatively high (98). Thus, whether there are any possible association between FBXW7 and KRAS mutations still needs further study. These data suggest that modulating ubiquitin ligases such as FBXW7 may impact the efficacy of cetuximab treatment for KRAS-negative CRC cancers.

\section{Conclusions and future direction}

Despite recent advances in detection and treatment, $\mathrm{CRC}$ is still a major global public health concern. It is the third most common cancer and the fourth leading cause of cancer-related deaths in the world (4); both the incidence and mortality rates of CRC are increasing rapidly in Asian countries (99). CRC is a consequence of the accumulation of both genetic and epigenetic genomic alterations. Over the past few years, a growing body of genetic alterations have been found to play an increasingly important role in CRC diagnosis and treatment. At present, kras alterations are identified for the purpose of guiding treatment with targeted therapies such as anti-endothelial growth factor receptor monoclonal antibodies clinically. Although our understanding of the molecular mechanisms of CRC has improved substantially, molecular biomarkers for predictive and prognostic purposes are still in the theory stage. Much remains to be discovered to fully appreciate the nature of FBPs in cancers. Identification of other FBPs and characterization of their contribution to $\mathrm{CRC}$ will be an important yet challenging task.

In the present review, we summarized the recent findings concerning FBPs in CRC (Fig. 2). Overall, on the basis of the data presented here, most studies have focused on characterizing the substrate networks of FBPs related with CRC, yet 
relatively little is known regarding the expression regulation of FBPs themselves that lead to human CRC carcinogenesis and development. In the future, it will be of great importance to identify novel FBPs and their substrates that regulate the development and progression of CRC. Recently, more and more data have shown that several molecules such as p53 and APC (14,70), miRNAs including miR-27a and miR-223 (95) as well as FBXW7 promoter hypermethylation (96) regulate the tumor suppressor functions of FBXW7. In this regard, a better understanding of the upstream regulators of FBPs in cancers is needed. We expect novel strategies that directly or indirectly target FBXW7 to obtain more effective treatment for cancer patients in the near future. In regards to CRC issues, a majority of studies were performed using immunohistochemistry (IHC) or polymerase chain reaction (PCR) to define a potential correlation in expression of FBPs and their substrates. Few studies have utilized in vivo mouse models. More genetically modified mouse models should be established for gut-specific transgenic expression to target relevant components. In addition, the FBXW7 status has currently been proven to be related to drug therapeutic effect $(98,100)$. Recent evidence reveals that bortezomib, a reversible inhibitor of the catalytic activity of the $26 \mathrm{~S}$ proteasome, can be efficacious in the treatment of human types of cancers $(101,102)$. This finding has set the stage for attempts to selectively inhibit the activities of disease-specific components of the UPS. All of these studies, therefore, call for an urgent need to design additional small molecules targeting FBP to treat human cancers. Future efforts in this area of research should be devoted to the development of small-molecule inhibitors of SCF E3 ligases as a novel approach for the treatment of human CRC. Moreover, the level of certain FBPs in cancers could be possible markers to optimize treatment regimens to achieve better clinical results.

\section{References}

1. Center MM, Jemal A and Ward E: International trends in colorectal cancer incidence rates. Cancer Epidemiol Biomarkers Prev 18: 1688-1694, 2009.

2. Center MM, Jemal A, Smith RA and Ward E: Worldwide variations in colorectal cancer. CA Cancer J Clin 59: 366-378, 2009.

3. Jemal A, Bray F, Center MM, Ferlay J, Ward E and Forman D: Global cancer statistics. CA Cancer J Clin 61: 69-90, 2011.

4. Siegel R, Ward E, Brawley O and Jemal A: Cancer statistics, 2011: The impact of eliminating socioeconomic and racial disparities on premature cancer deaths. CA Cancer J Clin 61: 212-236, 2011

5. Coppedè F, Lopomo A, Spisni R and Migliore L: Genetic and epigenetic biomarkers for diagnosis, prognosis and treatment of colorectal cancer. World J Gastroenterol 20: 943-956, 2014.

6. Liu J, Shaik S, Dai X, Wu Q, Zhou X, Wang Z and Wei W: Targeting the ubiquitin pathway for cancer treatment. Biochim Biophys Acta 1855: 50-60, 2015.

7. Genschik P, Sumara I and Lechner E: The emerging family of CULLIN3-RING ubiquitin ligases (CRL3s): Cellular functions and disease implications. EMBO J 32: 2307-2320, 2013.

8. Jadhav T and Wooten MW: Defining an embedded code for protein ubiquitination. J Proteomics Bioinform 2: 316-333, 2009.

9. Okamoto Y, Ozaki T, Miyazaki K, Aoyama M, Miyazaki M and Nakagawara A: UbcH10 is the cancer-related E2 ubiquitinconjugating enzyme. Cancer Res 63: 4167-4173, 2003.

10. Hou YC and Deng JY: Role of E3 ubiquitin ligases in gastric cancer. World J Gastroenterol 21: 786-793, 2015.

11. Zheng N, Schulman BA, Song L, et al: Structure of the Cul1Rbx1-Skp1-F box ${ }^{\text {Skp2 }}$ SCF ubiquitin ligase complex. Nature 416 703-709, 2002.

12. Nakayama KI and Nakayama K: Ubiquitin ligases: Cell-cycle control and cancer. Nat Rev Cancer 6: 369-381, 2006.
13. Santra MK, Wajapeyee N and Green MR: F-box protein FBXO31 mediates cyclin D1 degradation to induce G1 arrest after DNA damage. Nature 459: 722-725, 2009.

14. Agami R and Bernards R: Distinct initiation and maintenance mechanisms cooperate to induce $\mathrm{G} 1$ cell cycle arrest in response to DNA damage. Cell 102: 55-66, 2000.

15. Okabe H, Lee SH, Phuchareon J, Albertson DG, McCormick F and Tetsu O: A critical role for FBXW8 and MAPK in cyclin D1 degradation and cancer cell proliferation. PLoS One 1: e128, 2006.

16. Kumar R, Neilsen PM, Crawford J, et al: FBXO31 is the chromosome 16q24.3 senescence gene, a candidate breast tumor suppressor, and a component of an SCF complex. Cancer Res 65: 11304-11313, 2005.

17. Huang HL, Zheng WL, Zhao R, Zhang B and Ma WL: FBXO31 is down-regulated and may function as a tumor suppressor in hepatocellular carcinoma. Oncol Rep 24: 715-720, 2010.

18. Zhang X, Kong Y, Xu X, et al: F-box protein FBXO31 is downregulated in gastric cancer and negatively regulated by $\mathrm{miR}-17$ and miR-20a. Oncotarget 5: 6178-6190, 2014.

19. Kogo R, Mimori K, Tanaka F, Komune S and Mori M: FBXO3I determines poor prognosis in esophageal squamous cell carcinoma. Int J Oncol 39: 155-159, 2011.

20. Zhang H, Kobayashi R, Galaktionov K and Beach D: p19 $9_{S k p 1}$ and $\mathrm{p} 45_{S k p 2}$ are essential elements of the cyclin A-CDK2 S phase kinase. Cell 82: 915-925, 1995.

21. Hershko D, Bornstein G, Ben-Izhak O, Carrano A, Pagano M, Krausz MM and Hershko A: Inverse relation between levels of p27(Kip1) and of its ubiquitin ligase subunit Skp2 in colorectal carcinomas. Cancer 91: 1745-1751, 2001.

22. Mori M, Mimori K, Shiraishi T, Tanaka S, Ueo H, Sugimachi K and Akiyoshi T: p27 expression and gastric carcinoma. Nat Med 3: 593, 1997.

23. Fukuchi M, Masuda N, Nakajima M, Fukai Y, Miyazaki T, Kato H and Kuwano H: Inverse correlation between expression levels of p27 and the ubiquitin ligase subunit Skp2 in early esophageal squamous cell carcinoma. Anticancer Res 24: 777-783, 2004.

24. Masuda TA, Inoue H, Sonoda H, Mine S, Yoshikawa Y, Nakayama K, Nakayama K and Mori M: Clinical and biological significance of $S$-phase kinase-associated protein 2 (Skp2) gene expression in gastric carcinoma: Modulation of malignant phenotype by Skp2 overexpression, possibly via p27 proteolysis. Cancer Res 62: 3819-3825, 2002.

25. Yang G, Ayala G, De Marzo A, Tian W, Frolov A, Wheeler TM, Thompson TC and Harper JW: Elevated Skp2 protein expression in human prostate cancer: Association with loss of the cyclindependent kinase inhibitor p27 and PTEN and with reduced recurrence-free survival. Clin Cancer Res 8: 3419-3426, 2002.

26. Lu M, Ma J, Xue W, et al: The expression and prognosis of FOXO3a and Skp2 in human hepatocellular carcinoma. Pathol Oncol Res 15: 679-687, 2009.

27. Rose AE, Wang G, Hanniford D, et al: Clinical relevance of SKP2 alterations in metastatic melanoma. Pigment Cell Melanoma Res 24: 197-206, 2011.

28. Tosco P, La Terra Maggiore GM, Forni P, Berrone S, Chiusa L and Garzino-Demo P: Correlation between Skp2 expression and nodal metastasis in stage I and II oral squamous cell carcinomas. Oral Dis 17: 102-108, 2011.

29. Einama T, Kagata Y, Tsuda H, et al: High-level Skp2 expression in pancreatic ductal adenocarcinoma: Correlation with the extent of lymph node metastasis, higher histological grade, and poorer patient outcome. Pancreas 32: 376-381, 2006.

30. Voduc D, Nielsen TO, Cheang MC and Foulkes WD: The combination of high cyclin $\mathrm{E}$ and Skp2 expression in breast cancer is associated with a poor prognosis and the basal phenotype. Hum Pathol 39: 1431-1437, 2008.

31. Zhu CQ, Blackhall FH, Pintilie M, et al: Skp2 gene copy number aberrations are common in non-small cell lung carcinoma, and its overexpression in tumors with ras mutation is a poor prognostic marker. Clin Cancer Res 10: 1984-1991, 2004.

32. Gstaiger M, Jordan R, Lim M, Catzavelos C, Mestan J, Slingerland J and Krek W: Skp2 is oncogenic and overexpressed in human cancers. Proc Natl Acad Sci USA 98: 5043-5048, 2001.

33. Latres E, Chiarle R, Schulman BA, Pavletich NP, Pellicer A, Inghirami $G$ and Pagano M: Role of the F-box protein Skp2 in lymphomagenesis. Proc Natl Acad Sci USA 98: 2515-2520, 2001.

34. Dowen SE, Scott A, Mukherjee G and Stanley MA: Overexpression of Skp2 in carcinoma of the cervix does not correlate inversely with p27 expression. Int J Cancer 105: 326-330, 2003. 
35. Hershko DD and Shapira M: Prognostic role of $\mathrm{p} 27^{\text {Kipl }}$ deregulation in colorectal cancer. Cancer 107: 668-675, 2006.

36. Shapira M, Ben-Izhak O, Bishara B, et al: Alterations in the expression of the cell cycle regulatory protein cyclin kinase subunit 1 in colorectal carcinoma. Cancer 100: 1615-1621, 2004.

37. Li JQ, Wu F, Masaki T, Kubo A, Fujita J, Dixon DA, Beauchamp RD, Ishida T, Kuriyama $\mathrm{S}$ and Imaida K: Correlation of Skp2 with carcinogenesis, invasion, metastasis, and prognosis in colorectal tumors. Int J Oncol 25: 87-95, 2004.

38. Shapira M, Ben-Izhak O, Linn S, Futerman B, Minkov I and Hershko DD: The prognostic impact of the ubiquitin ligase subunits Skp2 and Cks1 in colorectal carcinoma. Cancer 103 1336-1346, 2005.

39. Xu SY, Wang F, Wei G, et al: S-phase kinase-associated protein 2 knockdown blocks colorectal cancer growth via regulation of both p27 and p16 expression. Cancer Gene Ther 20: 690-694, 2013.

40. Hristova NR, Tagscherer KE, Fassl A, Kopitz J and Roth W: Notch1-dependent regulation of p27 determines cell fate in colorectal cancer. Int J Oncol 43: 1967-1975, 2013.

41. Tian YF, Chen TJ, Lin CY, et al: SKP2 overexpression is associated with a poor prognosis of rectal cancer treated with chemoradiotherapy and represents a therapeutic target with high potential. Tumour Biol 34: 1107-1117, 2013.

42. Vedin LL, Gustafsson JA and Steffensen KR: The oxysterol receptors $L X R \alpha$ and $L X R \beta$ suppress proliferation in the colon. Mol Carcinog 52: 835-844, 2013

43. Wang Q, Zhou Y, Wang X and Evers BM: p27 $7^{\text {Kip1 }}$ nuclear localization and cyclin-dependent kinase inhibitory activity are regulated by glycogen synthase kinase-3 in human colon cancer cells. Cell Death Differ 15: 908-919, 2008.

44. Nishida N, Nagasaka T, Kashiwagi K, Boland CR and Goel A: High copy amplification of the Aurora-A gene is associated with chromosomal instability phenotype in human colorectal cancers. Cancer Biol Ther 6: 525-533, 2007.

45. Kleivi K, Lind GE, Diep CB, et al: Gene expression profiles of primary colorectal carcinomas, liver metastases, and carcinomatoses. Mol Cancer 6: 2, 2007.

46. Zhu J, Li K, Dong L and Chen Y: Role of FBXL20 in human colorectal adenocarcinoma. Oncol Rep 28: 2290-2298, 2012.

47. Zhu J, Deng S, Duan J, Xie X, Xu S, Ran M, Dai X, Pu Y and Zhang X: FBXL20 acts as an invasion inducer and mediates E-cadherin in colorectal adenocarcinoma. Oncol Lett 7 : 2185-2191, 2014

48. Shirane M, Hatakeyama S, Hattori K, Nakayama K and Nakayama K: Common pathway for the ubiquitination of IkappaBalpha, IkappaBbeta, and IkappaBepsilon mediated by the F-box protein FWD1. J Biol Chem 274: 28169-28174, 1999.

49. Spiegelman VS, Slaga TJ, Pagano M, Minamoto T, Ronai Z and Fuchs SY: Wnt/beta-catenin signaling induces the expression and activity of betaTrCP ubiquitin ligase receptor. Mol Cell 5: $877-882,2000$

50. Zhang N, Wei P, Gong A, et al: FoxM1 promotes $\beta$-catenin nuclear localization and controls Wnt target-gene expression and glioma tumorigenesis. Cancer Cell 20: 427-442, 2011.

51. Mokkapati S, Niopek K, Huang L, Cunniff KJ, Ruteshouser EC, deCaestecker M, Finegold MJ and Huff V: $\beta$-catenin activation in a novel liver progenitor cell type is sufficient to cause hepatocellular carcinoma and hepatoblastoma. Cancer Res 74 4515-4525, 2014

52. Wu Y, Deng J, Rychahou PG, Qiu S, Evers BM and Zhou BP: Stabilization of snail by NF-kappaB is required for inflammationinduced cell migration and invasion. Cancer Cell 15: 416-428, 2009.

53. Guardavaccaro D, Kudo Y, Boulaire J, Barchi M, Busino L, Donzelli M, Margottin-Goguet F, Jackson PK, Yamasaki L and Pagano M: Control of meiotic and mitotic progression by the F box protein beta-Trcp1 in vivo. Dev Cell 4: 799-812, 2003.

54. Kanarek N, Horwitz E, Mayan I, Leshets M, Cojocaru G, Davis M, Tsuberi BZ, Pikarsky E, Pagano M and Ben-Neriah Y: Spermatogenesis rescue in a mouse deficient for the ubiquitin ligase $\mathrm{SCF}^{\beta-\operatorname{TrCP}}$ by single substrate depletion. Genes Dev 24: 470-477, 2010.

55. Ougolkov A, Zhang B, Yamashita K, Bilim V, Mai M, Fuchs SY and Minamoto T: Associations among beta-TrCP, an E3 ubiquitin ligase receptor, beta-catenin, and NF-kappaB in colorectal cancer. J Natl Cancer Inst 96: 1161-1170, 2004.
56. Koch A, Waha A, Hartmann W, Hrychyk A, Schüller U, Waha A, Wharton KA Jr, Fuchs SY, von Schweinitz D and Pietsch T: Elevated expression of Wnt antagonists is a common event in hepatoblastomas. Clin Cancer Res 11: 4295-4304, 2005.

57. Müerköster S, Arlt A, Sipos B, Witt M, Grossmann M, Klöppel G, Kalthoff H, Fölsch UR and Schäfer H: Increased expression of the E3-ubiquitin ligase receptor subunit betaTRCP1 relates to constitutive nuclear factor-kappaB activation and chemoresistance in pancreatic carcinoma cells. Cancer Res 65: 1316-1324, 2005.

58. Liu J, Suresh Kumar KG, Yu D, Molton SA, McMahon M, Herlyn M, Thomas-Tikhonenko A and Fuchs SY: Oncogenic BRAF regulates beta-Trcp expression and NF-kappaB activity in human melanoma cells. Oncogene 26: 1954-1958, 2007.

59. Yaron A, Hatzubai A, Davis M, Lavon I, Amit S, Manning AM, Andersen JS, Mann M, Mercurio F and Ben-Neriah Y: Identification of the receptor component of the IkappaBalphaubiquitin ligase. Nature 396: 590-594, 1998.

60. Tsai WB, Chung YM, Zou Y, Park SH, Xu Z, Nakayama K, Lin SH and $\mathrm{Hu} \mathrm{MC}$ : Inhibition of FOXO3 tumor suppressor function by betaTrCP1 through ubiquitin-mediated degradation in a tumor mouse model. PLoS One 5: e11171, 2010.

61. Nakayama K, Hatakeyama S, Maruyama S, Kikuchi A, Onoé K, Good RA and Nakayama KI: Impaired degradation of inhibitory subunit of NF-kappa B (I kappa B) and beta-catenin as a result of targeted disruption of the beta-TrCP1 gene. Proc Natl Acad Sci USA 100: 8752-8757, 2003.

62. Saitoh T and Katoh M: Expression profiles of $\beta$ TRCP1 and $\beta \mathrm{TRCP} 2$, and mutation analysis of $\beta \mathrm{TRCP} 2$ in gastric cancer. Int J Oncol 18: 959-964, 2001.

63. Kim CJ, Song JH, Cho YG, Kim YS, Kim SY, Nam SW, Yoo NJ, Lee JY and Park WS: Somatic mutations of the beta-TrCP gene in gastric cancer. APMIS 115: 127-133, 2007.

64. Hartwell LH, Mortimer RK, Culotti J and Culotti M: Genetic control of the cell division cycle in yeast: V. genetic analysis of $c d c$ mutants. Genetics 74: 267-286, 1973.

65. Strohmaier H, Spruck CH, Kaiser P, Won KA, Sangfelt O and Reed SI: Human F-box protein hCdc4 targets cyclin E for proteolysis and is mutated in a breast cancer cell line. Nature 413: 316-322, 2001.

66. Spruck CH, Strohmaier H, Sangfelt O, Müller HM, Hubalek M, Müller-Holzner E, Marth C, Widschwendter M and Reed SI: $h C D C 4$ gene mutations in endometrial cancer. Cancer Res 62: 4535-4539, 2002.

67. Matsumoto A, Onoyama I and Nakayama KI: Expression of mouse Fbxw7 isoforms is regulated in a cell cycle- or p53-dependent manner. Biochem Biophys Res Commun 350: 114-119, 2006.

68. Welcker M, Orian A, Grim JE, Eisenman RN and Clurman BE: A nucleolar isoform of the Fbw7 ubiquitin ligase regulates c-Myc and cell size. Curr Biol 14: 1852-1857, 2004.

69. Crusio KM, King B, Reavie LB and Aifantis I: The ubiquitous nature of cancer: The role of the $\mathrm{SCF}^{\mathrm{Fbw} 7}$ complex in development and transformation. Oncogene 29: 4865-4873, 2010.

70. Mao JH, Perez-Losada J, Wu D, Delrosario R, Tsunematsu R, Nakayama KI, Brown K, Bryson S and Balmain A: Fbxw7/Cdc4 is a p53-dependent, haploinsufficient tumour suppressor gene. Nature 432: 775-779, 2004

71. Grim JE, Knoblaugh SE, Guthrie KA, et al: Fbw7 and p53 cooperatively suppress advanced and chromosomally unstable intestinal cancer. Mol Cell Biol 32: 2160-2167, 2012.

72. Rajagopalan H, Jallepalli PV, Rago C, Velculescu VE, Kinzler KW, Vogelstein B and Lengauer C: Inactivation of $h C D C 4$ can cause chromosomal instability. Nature 428: 77-81, 2004.

73. Stamatakos M, Palla V, Karaiskos I, Xiromeritis K, Alexiou I, Pateras I and Kontzoglou K: Cell cyclins: Triggering elements of cancer or not? World J Surg Oncol 8: 111, 2010.

74. Buckley MF, Sweeney KJ, Hamilton JA, Sini RL, Manning DL, Nicholson RI, deFazio A, Watts CK, Musgrove EA and Sutherland RL: Expression and amplification of cyclin genes in human breast cancer. Oncogene 8: 2127-2133, 1993.

75. Shinozaki H, Ozawa S, Ando N, Tsuruta H, Terada M, Ueda M and Kitajima M: Cyclin D1 amplification as a new predictive classification for squamous cell carcinoma of the esophagus, adding gene information. Clin Cancer Res 2: 1155-1161, 1996.

76. Ikeguchi M, Sakatani T, Ueta T and Kaibara N: Cyclin D1 expression and retinoblastoma gene protein (pRB) expression in esophageal squamous cell carcinoma. J Cancer Res Clin Oncol 127: 531-536, 2001. 
77. Sionov RV, Netzer E and Shaulian E: Differential regulation of FBXW7 isoforms by various stress stimuli. Cell Cycle 12: 3547-3554, 2013

78. Grim JE, Gustafson MP, Hirata RK, Hagar AC, Swanger J, Welcker M, Hwang HC, Ericsson J, Russell DW and Clurman BE: Isoform- and cell cycle-dependent substrate degradation by the Fbw7 ubiquitin ligase. J Cell Biol 181: 913-920, 2008

79. van Drogen F, Sangfelt O, Malyukova A, Matskova L, Yeh E, Means AR and Reed SI: Ubiquitylation of cyclin $\mathrm{E}$ requires the sequential function of SCF complexes containing distinct hCdc4 isoforms. Mol Cell 23: 37-48, 2006.

80. Sangfelt O, Cepeda D, Malyukova A, van Drogen F and Reed SI: Both SCF ${ }^{\text {Cdc4alpha }}$ and SCF Cdc4gamma $_{\text {are }}$ required for cyclin E turnover in cell lines that do not overexpress cyclin E. Cell Cycle 7: 1075-1082, 2008.

81. Tang X, Orlicky S, Lin Z, Willems A, Neculai D, Ceccarelli D, Mercurio F, Shilton BH, Sicheri F and Tyers M: Suprafacial orientation of the $\mathrm{SCF}^{\mathrm{Cdc} 4}$ dimer accommodates multiple geometries for substrate ubiquitination. Cell 129: 1165-1176, 2007.

82. Welcker $M$ and Clurman BE: Fbw7/hCDC4 dimerization regulates its substrate interactions. Cell Div 2: 7, 2007.

83. Iwatsuki M, Mimori K, Ishii $\mathrm{H}$, et al: Loss of FBXW7, a cell cycle regulating gene, in colorectal cancer: Clinical significance. Int J Cancer 126: 1828-1837, 2010.

84. Fukushima $\mathrm{H}$, Matsumoto A, Inuzuka $\mathrm{H}$, et al: $\mathrm{SCF}^{\mathrm{Fbw} 7}$ modulates the $\mathrm{NF} \kappa \mathrm{B}$ signaling pathway by targeting $\mathrm{NF} \kappa \mathrm{B} 2$ for ubiquitination and destruction. Cell Rep 1: 434-443, 2012.

85. Guo Z, Zhou Y, Evers BM and Wang Q: Rictor regulates FBXW7-dependent c-Myc and cyclin E degradation in colorectal cancer cells. Biochem Biophys Res Commun 418: 426-432, 2012.

86. Wang Y, Liu Y, Lu J, Zhang P, Wang Y, Xu Y, Wang Z, Mao JH and Wei G: Rapamycin inhibits FBXW7 loss-induced epithelialmesenchymal transition and cancer stem cell-like characteristics in colorectal cancer cells. Biochem Biophys Res Commun 434: 352-356, 2013

87. Tetzlaff MT, Yu W, Li M, Zhang P, Finegold M, Mahon K, Harper JW, Schwartz RJ and Elledge SJ: Defective cardiovascular development and elevated cyclin E and Notch proteins in mice lacking the Fbw7 F-box protein. Proc Natl Acad Sci USA 101: 3338-3345, 2004

88. Sancho R, Jandke A, Davis H, Diefenbacher ME, Tomlinson I and Behrens A: F-box and WD repeat domain-containing 7 regulates intestinal cell lineage commitment and is a haploinsufficient tumor suppressor. Gastroenterology 139: 929-941, 2010.

89. Babaei-Jadidi R, Li N, Saadeddin A, et al: FBXW7 influences murine intestinal homeostasis and cancer, targeting Notch, Jun, and DEK for degradation. J Exp Med 208: 295-312, 2011.
90. Davis H, Lewis A, Behrens A and Tomlinson I: Investigation of the atypical $F B X W 7$ mutation spectrum in human tumours by conditional expression of a heterozygous propellor tip missense allele in the mouse intestines. Gut 63: 792-799, 2014.

91. Jahid S, Sun J, Edwards RA, Dizon D, Panarelli NC, Milsom JW, Sikandar SS, Gümüs ZH and Lipkin SM: $m i R-23 a$ promotes the transition from indolent to invasive colorectal cancer. Cancer Discov 2: 540-553, 2012.

92. Akhoondi S, Lindström L, Widschwendter M, Corcoran M Bergh J, Spruck C, Grandér D and Sangfelt O: Inactivation of $F B X W 7 / h C D C 4-\beta$ expression by promoter hypermethylation is associated with favorable prognosis in primary breast cancer. Breast Cancer Res 12: R105, 2010.

93. Kemp Z, Rowan A, Chambers W, et al: CDC4 mutations occur in a subset of colorectal cancers but are not predicted to cause loss of function and are not associated with chromosomal instability. Cancer Res 65: 11361-11366, 2005.

94. Mouradov D, Domingo E, Gibbs P, et al: Survival in stage II/III colorectal cancer is independently predicted by chromosomal and microsatellite instability, but not by specific driver mutations. Am J Gastroenterol 108: 1785-1793, 2013.

95. Miyaki M, Yamaguchi T, Iijima T, Takahashi K, Matsumoto $\mathrm{H}$ and Mori T: Somatic mutations of the CDC4 (FBXW7) gene in hereditary colorectal tumors. Oncology 76: 430-434, 2009.

96. Voorham QJ, Carvalho B, Spiertz AJ, et al: Comprehensive mutation analysis in colorectal flat adenomas. PLoS One 7: e41963, 2012.

97. Xie T, Cho YB, Wang K, et al: Patterns of somatic alterations between matched primary and metastatic colorectal tumors characterized by whole-genome sequencing. Genomics 104: 234-241, 2014

98. Jardim DL, Wheler JJ, Hess K, et al: FBXW7 mutations in patients with advanced cancers: Clinical and molecular characteristics and outcomes with mTOR inhibitors. PLoS One 9: e89388, 2014.

99. Sung JJ, Ng SC, Chan FK, et al: An updated Asia Pacific Consensus Recommendations on colorectal cancer screening. Gut 64: 121-132, 2015.

100. Wertz IE, Kusam S, Lam C, et al: Sensitivity to antitubulin chemotherapeutics is regulated by MCL1 and FBW7. Nature 471: 110-114, 2011.

101. Alinari L, White VL, Earl CT, et al: Combination bortezomib and rituximab treatment affects multiple survival and death pathways to promote apoptosis in mantle cell lymphoma. MAbs 1: 31-40, 2009

102. Kane RC, Bross PF, Farrell AT and Pazdur R: Velcade: U.S. FDA approval for the treatment of multiple myeloma progressing on prior therapy. Oncologist 8: 508-513, 2003. 